may exist, and occasional tonics and stimulants, are the appropriate remedies in these cases, and renerally in time effect a cure. We know very little of the pathology of this disease, and we therefore suppose it to have something to do with the great sympathetic nerve, and the ganglionic system connected therewith; but about all these matters I must confess to you that we know very little, and therefore it is that I have very little to say to you about it.

\section{HYPERTROPHY OF THE PAROTID GLAND.}

TO THE EDITORS OF THE PROVINCIAL MEDICAL AND SURGICAL JOURNAI.

Gentremen,--Should you deem the accompanying case sufficiently interesting, will you do me the favour to insert it in your Journal of next week? Your obedient servant,

Abraham Duke,

Surgeon to the Chichester Infirmary.

Chichester, Feb. 10, 1842.

Sarah Mantle, aged 9 months, has, from the age of three weeks, been affected with a tumour on the left side of the face and neck. When first perceived, the parents state it was about the size of a pea, and was situated in front and below the ear; the skin covering it was not at all discoloured, but the temperature of the part was higher than natural. The swelling continued to increase rapidly, and at the end of two months it had attained such a size that the friends of the child began to be much alarmed. I saw it for the first time when it was about three months old, and the tumour then occupied the side of the face and upper part of the neck. The child appeared to enjoy good health (although somewhat emaciated) up to the age of six months, when it was seized with convulsions, which returned at irregular intervals; between these attacks the child seemed quite well, its appetite being very good, and the bowels in a regular state. On Sunday, the 23rd of January, 1842, the convulsions returning, I was sent for, and before I could reach the house the poor little sufferer had breathed its last. An examination of the body took place the following day. The tumour had increased to an enormous size, and extended from a line drawn from the external angle of the orbit to two-thirds down the neck (the lowest part of it hanging detached, and resting on the upper part of the chest), as far back as a little behind the mastoid process, and occupying two-thirds of the cheek in front. Underneath the chin the tumour advances somewhat beyond its centre, and is studded there, as well as at its posterior part, with several small and one or two larger nevi. The tumour feels as if it contained cysts, and the superficial veins are large and tortuous. On removing the coverings of the swelling, the external jugular vein was seen to bo very much enlarged, and exceedingly irregular in its course, and could be traced deeply into the substance of the tumour. A large vein, running in the course of the common carotid, but rather more superficially, was at first sight supposed to be the internal jugular; but, on opening the sheath, that vessel was found in its natural situation, but, like the external, was much increased in size. The common carotid, as well as the external, presented no marks of disease whatever the latter was traced through the substance of the tumour, and was found occupying its natural position. On making a section of the tumour, it presented a perfectly glandular structure, and appeared to be nothing more than simple hypertrophy of the parotid gland. The head was not examined.

REMARKS.

I have been induced to publish this case, in order to put others on their guard in forming a proguosis on tumours in this situation. The subject of this case had been seen by most of the medical men in this city, and some of them, with myself, were of opinion that it was a case of ancurism by anastomosis, and recommended the tying of the carotid on the affected side for its removal. This, however, the parents refused to have done, and, had they consented to the operation, I am decidedly of opinion that no permanent benefit could have resulted; besides which, owing to the size of the swelling, much difficulty would have been experienced from the depth of the vessel, as well as from the number of enlarged veins in the neighbourhood. The child had not cut any of its teeth, and it was only about a month previous to its death that it began to lose flesh, and this probably was owing to so much blood having been required for the support of so large a swelling.

\section{CASES OF SOLAR ASPHYXIA, WITH DISSECTIONS.}

By B. Dowler, M.D., of New Orleans.

June 19, 1841. James Stevenson, a stout, muscular man, aged about 35 years, a cooper, for six months a resident of this city, ate his dinner in good health, and after walking about three hours on the Levee, complained that he could not sweat as usual; he requested one of his friends to put his hand upon his (Stevenson's) breast, which he found very hot and dry. Stevenson started home, but fell, before he reached his house, in Joseph-street. Some passers-by said that he was drunk; others, finding no scent of spirituous liquors in his breath, ran instantly for aid.

The skin was much hotter than in the most burning fever; on holding the hand near the body, a strong sensation of heat radiating from it was perceptible. The pulse was quick, gaseous, variable, and hobbling ; sometimes throbbing and full, especially in the arterics of the neck; from a vein, opened in the arm, the blood trickled down at first, but started soon into a full stream, and, falling upon the hands of an attendant, he declared that it was almost "scalding hot." The breathing was irregular and laborious; the larynx, moving up and down two or three inches during each respiration, which was attended with fits of strangling, and loud phlegmy rattles, and occasionally a kind of imperfect involuntary cough, bringing a tenacious froth in to the nose and mouth.

During inspiration, the expansion of the chest was very imperfect, as if the respiratory muscles had been palsied or disabled, reminding the observer, also, of a patient having broken ribs, in which full expansion or elevation of the ribs gives pain, and is, therefore, avoided.

While Stcvenson's chest was comparatively quiescent, the windpipe and abdomen moved and heaved with great violence.

$\mathrm{He}$ was wholly insensible, and was unable to swallow; the eyelids were nearly closed, and the pupils somewhat contracted; no distortion of features; the under jaw slightly fallen; no muscular contractions or convulsions; died in an hour.

Shields, one of his companions, died at the same time, from the same disease; he lived at the same house; had been in the city the same length of time ; was about the same age; followed the cooper's trade. He ate his dinner as usual, and worked several hours, and died not far from his boarding-house.

On Sunday morning, about sixteen hours after death, I examined their bodies, in the presence of a 